\title{
Language and Context in Mathematical Problem Solving: A Threat to Students' Performance
}

\section{and Assessment}

* Dr. Muhammad Ilyas Mahmood, Head (Corresponding Author)

** Mobashra Mobeen, Visiting Lecturer

*** Sajid Abbas

\begin{abstract}
The study recognizes that word problems are the necessary part and a key component of mathematics education. Knowing that mathematics, language as a means, and the situation context are never separable, the study was designed to identify the effect of language $(L 1, L 2)$ and the context on problem solving in mathematics for $2^{\text {nd }}, 3^{\text {rd }}$, and $4^{\text {th }}$ grader English as a second language (ESL) learners. For this, four achievement tests with possible variations of language and context were utilized as instrument to investigate three research questions. 867 students from three existing scenarios of school mathematics learning in Pakistan participated in the study. The data were analyzed through SPSS utilizing both descriptive as well as inferential methods. The results revealed that language and context have significant effect on problem solving. The study exposed that mathematical problem-solving assessments cannot be called valid if the factors of language and context are not taken into consideration. Learners' first language was strongly recommended for teaching mathematics at low levels. This study will uniquely contribute to understanding and determining the due role of language in mathematics learning, performance, and assessments in all educational contexts.
\end{abstract}

Keywords: Context and Language; Mathematical Problem Solving; Performance Assessment; Word Problems

\section{Introduction}

Mathematics has always been considered a difficult subject for students in all ages. The difficulty of the students is added when mathematical skills are combined with language, as numerous studies have pointed out that language is one of the most stumbling blocks for understanding of mathematics, especially for those students who are learning mathematics in their second or third language (Mizala, Martínez \& Martínez, 2015). In such situations, a lesson of mathematics is usually a language lesson within the mathematical part. The major example of this type is mathematical word problems. Word problems in mathematics are often considered to be the most challenging form of questions for students at all levels. Studies have found that there is a significant relationship between students' language proficiency and performance in mathematical word problems (Takeuchi, 2016).

Solving mathematical word problems is an essential part of mathematics education because these problems let students apply their mathematics understanding and skills to real-world affairs. In this regard, a greater emphasis has been placed on pupils' mathematical problem-solving skill.

The most fundamental difficulty that students face in solving word problems exists in the capacity to comprehend the mathematical problem structure which is rooted in the problem text. Difficulty with understanding the problem structure very often leads to errors in the selection of the solution procedure.

The situation becomes worse when the students are dealing mathematics in a second or foreign language with non-local context. In this phenomenon, there exist the following three possibilities:

a. Second language environment, second/foreign language mathematics, and second/foreign

* Department of English, Centre for English Language \& Learning,University of Okara, Pakistan

Email: ilyas.edu.tesl@gmail.com

** Centre for English Language \& Learning, University of Okara, Pakistan

*** Punjab Government School Education Department, Punjab, Pakistan 
language students.

b. First language environment, second/foreign language mathematics with non-local context, and second/foreign language students.

c. First language environment, second/foreign language mathematics with local context, and second/foreign language students.

There is abundance of literature available to support assumptions. Some reports of the type are summarized as following:

a. Second language learners of English perform less in mathematics word problems presented in English than those whose first language is English (Barton, Chan, King, Neville-Barton \& Sneddon, 2005).

b. Non-English students in non-English environment face difficulty in understanding word problems presented in English and show less results than offered in their first language (Ri'orda' in \& Donoghue, 2007).

c. Other than it, the issue of students' context and culture in the understanding and solving of word problems in mathematics has also been a discussion in various studies, showing that students perform better in contextualized word problems than in de-contextualized and culturally irrelevant (Hoth, Döhrmann, Kaiser, Busse, König, \& Blömeke, 2016).

d. Various studies (Roberts \& Bryant, 2011) also demonstrate that student's performance in solving the word problems is affected by changes in the linguistic form of word problem texts e.g. De-Corte et al. (1985) re-worded subtraction problems in order to make relations more explicit among the known and unknown quantities. The re-worded problems were solved much better by their subjects than the ones with standard wording. They suggested that these linguistic changes caused variations in the ease with which the relationships among the quantitative information are comprehended, which influenced the solution procedures.

In Pakistan, there are working the following three systems of mathematics education in isolation:

a. Public sector till recent past was using mathematics in Urdu, but now shifted to English as language of mathematics at all levels, using mathematics books published by Punjab Textbook Board in the local context.

b. Private schools using localized editions (with local context) of mathematics in English language by private publishers e.g. Countdown, Pakistani version published by Oxford, Sunrise Math by Sunrise publishers etc.

c. Private schools using foreign published mathematics books written in English with foreign context e.g. Ginn Series published by Oxford, SPMG New Heinemann Maths published by Heinemann, Math-Smart by Alston, Mathematics Pupil's Book by Macmillan etc.

The available literature cautions that our mathematics students, in all the above three situations, would most probably be suffering and their performance in mathematics word problems might have been affected by language and context as factors. This might be the reason that our school students are weak in the subject of mathematics. This attitude might have lessened the interest of little students in mathematics, affected their results and misdirected the stakeholders and decision making. Commenting on the issue of language in mathematics in this regard, Brahier (2016) and pointed out that, though teachers have often assumed that incorrect solutions to word problems are the product of lack of understanding of mathematical concepts or inadequacy of computing skills, in fact, the errors are the cause of an insufficient comprehension of the language of mathematics.

The present study, thus, intended to accumulate first-hand data from Pakistani students to collect evidences for/contrary to the literature available from studies outside Pakistan on the issue of language and context in mathematics. Besides this, since not all research studies find that the use of first language facilitates problem solution (Oviedo, 2005), one should be cautious generalizing findings of studies reporting first language advantage (Bernardo \& Calleja, 2005). Further, it is very difficult also to compare and generalize findings from one situation to another on account of the differences in curricula, pedagogies, age cohorts, language development, cognitive abilities, social backgrounds, etc. (Kempert, Saalbach \& Hardy, 2011).

Word problems were taken as the base of the study for two significant reasons (Gurganus, 2017). Firstly, problem solving has always been an integral part of mathematics instruction. Verschaffel, Greer, and De Corte (2000) report that problem solving can be had in 4,000-year-old 
Egyptian papyri, in Greek and Roman manuscripts, and in the arithmetic textbooks, printed in the earliest times. At present, efforts to determine mathematics achievement across various countries depend heavily on word problems. Secondly, word problems have clear linguistic components because the problem elements are rooted within a text.

This study was embedded in the assumption that language and context affect problem solving in mathematics.

\section{Research Questions}

The study aimed to find answers to the following questions:

(i). Is there any difference in students' performance in word problems presented in L1 (Urdu) and L2 (English)?

(ii). Is there any difference in students' performance in word problems presented in L1 (Urdu) and numeric (no language, just numbers)?

(iii). Is there any difference in students' performance in word problems presented in L2 (English) with foreign context (British) and in L2 (English) with students' own context (Pakistani)?

Unlike other subjects, prevailing practice in assessment of mathematics is based on measuring students' mathematical skills in isolation to their language capabilities. Language competencies are considered an unrelated factor in learning and performance of students in mathematics.

The findings of this study would create awareness among stakeholders about the due role of language in mathematics learning and performance. By implications, teachers can be trained to carefully use language, select books which are contextually relevant and acceptable in terms of language difficulty.

The results of the study would also uniquely contribute to making judicial interpretation of students' performance in mathematics. The knowledge of potential language interference can be filtered by teachers/evaluators who assess students' performance in mathematical word problems. The practice of attributing poor performance to poor mathematical skills might be misleading when language interference is ignored.

There has been a growing school of thought advocating universality of mathematics that mathematics is a culture free entity. The results of the study would put forward an argument showing the tentativeness of the belief of this school of thought.

The study was delimited to early grades (i.e. grade 2,3, and 4) from all the three existing situations in Pakistan. Early grade students were chosen deliberately with a rationale that it is a growing age where language learning is yet in the initial stages, and thus insufficiency of language can affect students' performance.

\section{Methodology}

The study was descriptive in nature and survey in type as quantitative data was collected through four different versions of tests. This study was framed by sociocultural perspective and positivist paradigm.

\section{Population}

The following three categories of schools were included in the population:

a. All public sector schools in the Punjab province using mathematics in English with local context, published by Punjab Textbook Board. Till recent past these schools were using mathematics in Urdu with local context.

b. Private schools in the Punjab province using localized editions (with local context) of mathematics in English language by private publishers e.g. e.g. Countdown, Pakistani version published by Oxford, Sunrise Math by Sunrise publishers etc.

c. Private schools in the Punjab province using foreign published mathematics books written in English with foreign context e.g. Ginn Series published by Oxford, SPMG New Heinemann Maths published by Heinemann, Math-Smart by Alston, Mathematics Pupil's Book by Macmillan etc.

\section{Sample}

The study involved 867 2nd, 3rd and 4rth graders in total. The ages of the students ranged from 6-10 years. All students reported Urdu to be their first language (L1) and were being taught mathematics in English (L2) as primary language with materials and assessments in English.

\section{Development of Instruments}

As this study aimed to see the effect of language and context on mathematical problem solving among 
grade 2, 3, and 4 learners of English as second language, four tests with foreign and local language and contexts were decided as instruments for the study. No other method was felt required for data collection as these tests were thought to provide direct and exact information of the effect of the said factors on students' mathematical problem solving. The nature of the developed four versions of the tests was as below:

Table 1

The Nature of Four Versions of Tests

\begin{tabular}{ll}
\hline Tests & Nature \\
\hline Test A & Foreign language (English as second language) and foreign context \\
Test B & Foreign language (English as second language) and local context \\
Test C & First language (Urdu) and local context \\
Test D & No language and no context, just numbers. \\
\hline
\end{tabular}

In addition to above mentioned tests, the following few questions about students' background variables and associated information were included in the Test $\mathrm{D}$, which were later used for analysis:

a. Which language the students used the most

b. Their previous school(s) if other than the present

c. Their level of proficiency in all the four language skills.

Each version of test had 16 questions (4 of addition, 4 of subtraction, 4 of multiplication, and 4 of division). The table below provides details of the instruments:

Table 2

Details of the Instruments

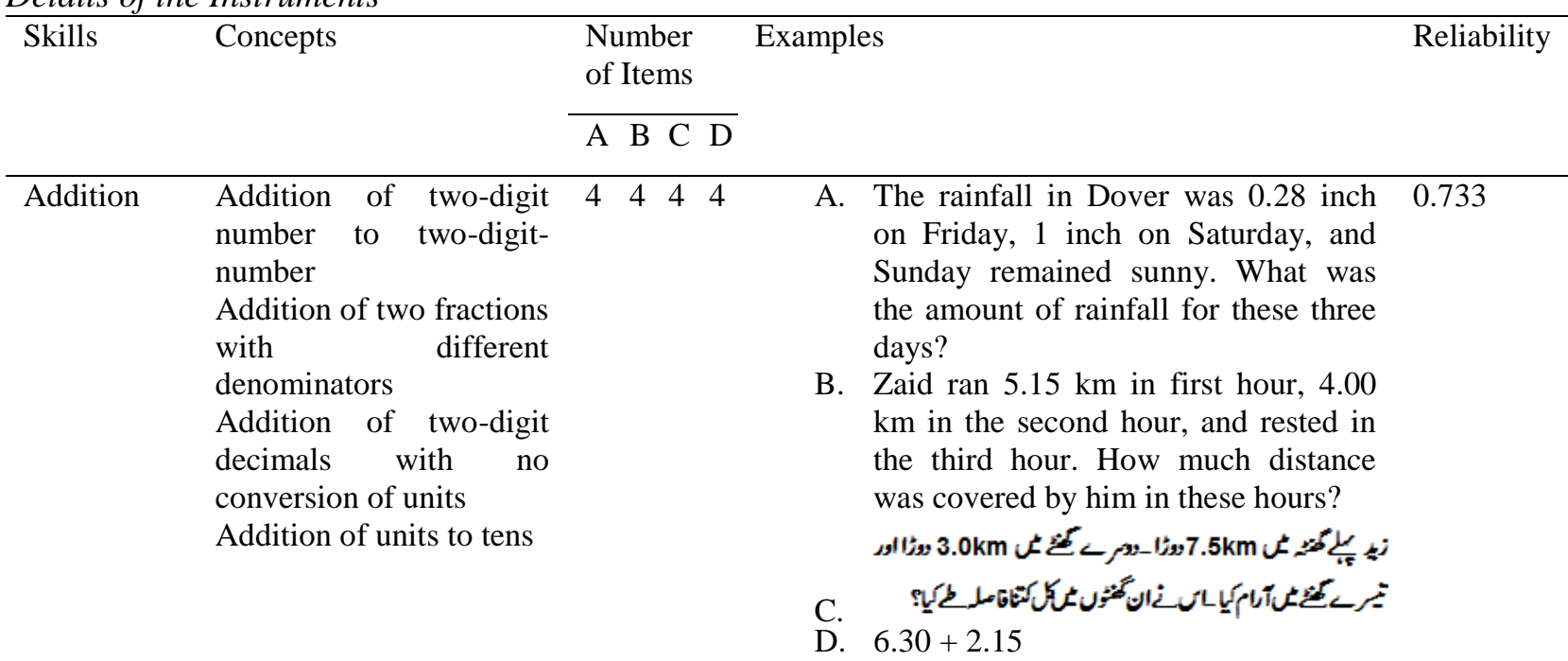

Subtraction Subtraction of two-digit $4 \begin{array}{llll}4 & 4 & 4\end{array}$ numbers

Subtraction of two-digit

fractions

Subtraction of two-digit decimals

Subtraction of units from tens
A. The Buffalo Wildcats scored 42 points and The New York Bulldogs scored 27 points in a rugby game. How many more points did the Wildcats score than the Bulldogs?

B. Afridi scored 96 runs and Kamran scored 74 runs in a cricket match. How many runs more did Afridi score than Kamran?

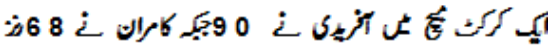

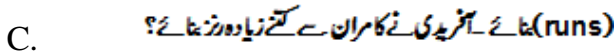

D. $78-26$ 


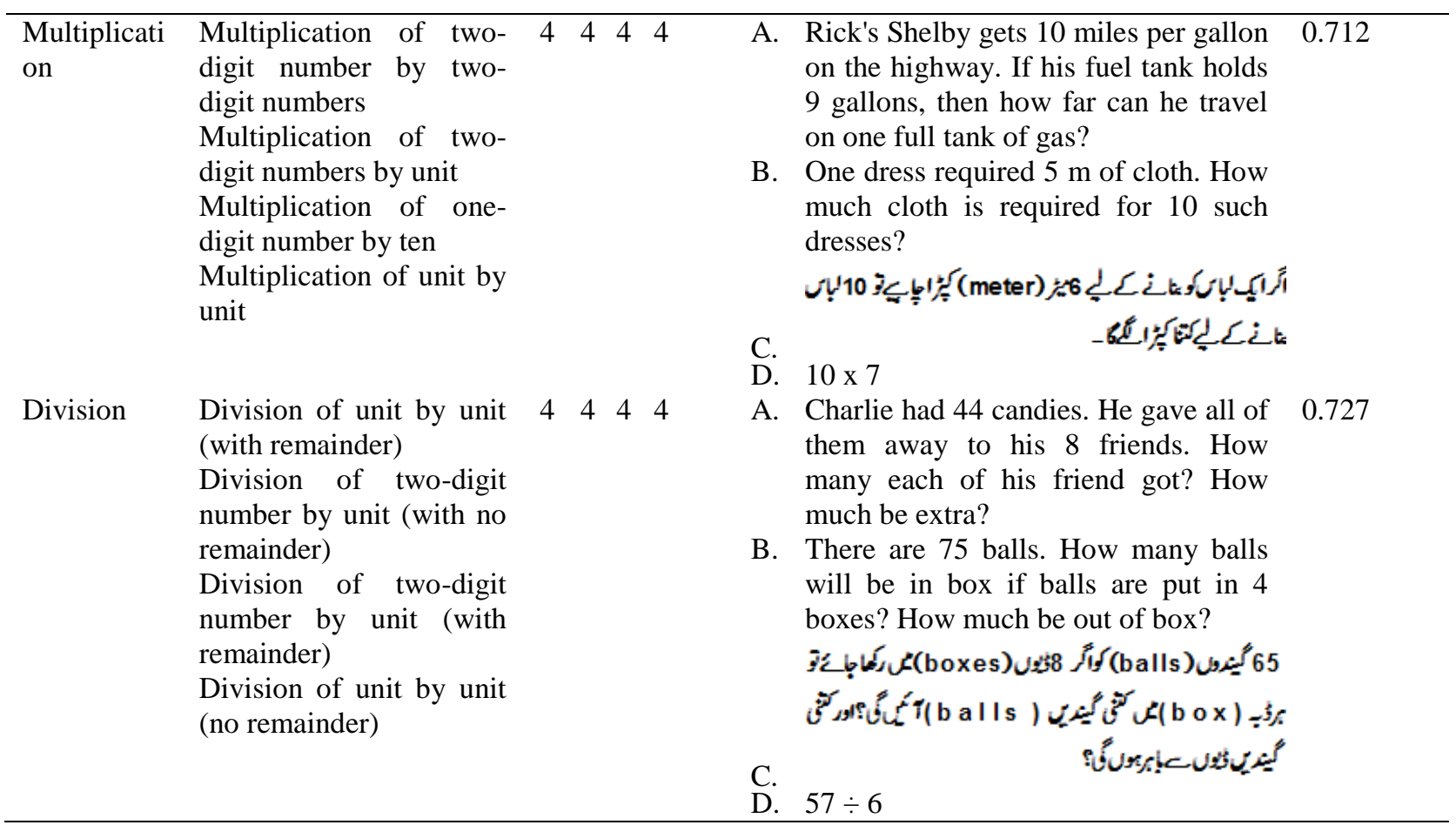

Areas of mathematics were selected based on review of various textbooks used in selected schools, so that context does not become a source of variation. The rationale for localization of context is demonstrated in the table 3 given below:

Table 3

Basis of Difference in Contexed Language in Test A and B

\begin{tabular}{lll}
\hline Example & & Rationale \\
\hline $\begin{array}{l}\text { Test A (Foreign Language, Foreign } \\
\text { Context) }\end{array}$ & $\begin{array}{l}\text { Test B (Foreign Language, } \\
\text { Local Context) }\end{array}$ \\
$\begin{array}{l}\text { Marla, Berkeley, and Ryan each } \\
\text { Ali has } 46 \text { stamps. His brother }\end{array}$ & $\begin{array}{l}\text { 1. Names of places changed } \\
\text { a bag of jellybeans. Marla's }\end{array}$ \\
gag has 34 jellybeans in it. have the collection of 1000 & $\begin{array}{l}\text { Used local names instead of foreign } \\
\text { names }\end{array}$ \\
$\begin{array}{l}\text { Berkeley's bag had } 16 \text { jellybeans. stamps. How many stamps he } \\
\text { Ryan's bag has no beans in it. has now? }\end{array}$ & $\begin{array}{l}\text { Things and commodities used in } \\
\text { society were preferred. }\end{array}$ \\
$\begin{array}{l}\text { What is the total number of } \\
\text { jellybeans they had? }\end{array}$ & $\begin{array}{l}\text { Familiar activities were used in } \\
\text { questions to ask mathematical } \\
\text { problems. }\end{array}$
\end{tabular}

Problems in the 'Base Test' (Test A) were selected from various sources recommended for Grade 2, 3, and 4. For the Test 'B' every possible effort was made to make the problems reflect students' own context from all dimensions.

The tests were very carefully constructed, consulted, piloted, revised, and improved. Level of difficulty was very sense-fully maintained in single-concept items across all the four tests (see Appendix ' $A$ ').

Questions of addition, subtraction, multiplication, and division were ordered by complexity of concepts involved and the order decided was followed in all the four tests e.g. question 1 in test A, B, $\mathrm{C}$, and D was of same concept. Each test was of two pages (one leaf, back to back). Required instructions were very clearly stated in the start of the paper. Invigilators were advised not to provide any clue.

While developing of word problems for all the tests key words were avoided so that accurate results could be attained as 'some of the students utilize 'superficial coping strategies' (Verschaffel \& De Corte, 1997, p. 86) as selecting a solution strategy based on some keywords (e.g. 'left', 'more', 'altogether' etc.).'

\section{Validation of Instruments}

To ensure the validity of the tests, researchers with mathematics and language backgrounds were consulted for more than one time and improvements were made followed by a criterion developed. 
Tests were pilot tested on one section each of class 2,3 , and 4 . The total number of the students was 92. The standards for Cronbach's Alpha and items reliability were justified.

\section{Data Analysis Methods}

In our data set we had four very important metric variables which consisted of scores of test A, B, C and D except other demographic nature of variables. For Statistical analysis both approaches descriptive statistics as well as inferential statistics were adopted to satisfy our research objectives. In descriptive statistics, mean, standard deviation and standard error of different variables were calculated. In inferential statistics, as our variables of interest fulfilled the assumptions of parametric test statistics, we used t-test pair wise for checking the equality of mean of above-mentioned different metric variables. To check the effect size, eta-squared index was calculated. All the above-mentioned statistical analysis was performed using Statistical Package for Social Sciences (SPSS).

\section{Results}

The readings from the data are presented here.

\section{Overall Performance of Students on Four Tests}

Table 4

Description of Students' Performance on Four Tests

\begin{tabular}{llll}
\hline Type of Test & N & X & SD \\
\hline Test A & 851 & 6.12 & 3.419 \\
Test B & 849 & 7.04 & 3.634 \\
Test C & 829 & 7.95 & 3.305 \\
Test D & 845 & 9.65 & 3.413 \\
\hline
\end{tabular}

Minimum possible score was zero; maximum possible score was 16

Test A- Foreign language (English as second language) and foreign context

Test B- Foreign language (English as second language) and local context

Test C- Local language (Urdu) and local context

Test D- No language and no context, just numbers (numeric)

Table 4 shows that irrespective of the variations in test forms, the performance of students in mathematics is below average (test $A=6.12$, test $B=7.04$, test $C=7.95$ ) or around (test $D=9.65$ ). It means mathematics is a difficult subject for students.

An increase in scores has been noted with step wise elimination of language. Localization of context of word problems projects improvement in the performance/results of students.

\section{Performance on Four Tests by Students' Types (School Wise)}

Table 5

Description of Students' Performance in Four Tests by Students' Types

\begin{tabular}{lllllllllllll}
\hline & \multicolumn{3}{l}{ School 1 } & \multicolumn{4}{c}{ School 2 } & \multicolumn{3}{c}{ School 3 } & \multicolumn{3}{c}{ School 4 } \\
\cline { 2 - 13 } Type of Test & $\mathrm{N}$ & $\mathrm{X}$ & $\mathrm{SD}$ & $\mathrm{N}$ & $\mathrm{X}$ & $\mathrm{SD}$ & $\mathrm{N}$ & $\mathrm{X}$ & $\mathrm{SD}$ & $\mathrm{N}$ & $\mathrm{X}$ & SD \\
\hline Test A & 293 & 7.80 & 3.032 & 248 & 7.09 & 3.414 & 159 & 3.87 & 2.176 & 151 & 3.62 & 2.349 \\
Test B & 292 & 8.87 & 2.982 & 246 & 8.02 & 3.611 & 159 & 4.77 & 2.726 & 152 & 4.28 & 2.643 \\
Test C & 283 & 9.13 & 2.844 & 243 & 8.56 & 3.390 & 157 & 6.65 & 2.948 & 146 & 6.03 & 3.039 \\
Test D & 288 & 10.63 & 3.426 & 245 & 9.96 & 3.620 & 160 & 8.69 & 2.907 & 152 & 8.28 & 2.806 \\
\hline
\end{tabular}

School 1 = Private school using foreign published mathematics books written in English with foreign context, School 2 = Private school using localized editions (with local context) of mathematics in English language by private publishers, School 3 = Public Sector School-Girls (using mathematics in English with local context, published by Punjab Text Book Board, School $4=$ Public Sector SchoolBoys ((using mathematics in English with local context, published by Punjab Text Book Board)

Test A- Foreign language (English as second language) and foreign context

Test B- Foreign language (English as second language) and local context

Test C- Local language (Urdu) and local context

Test $\mathrm{D}$ - No language and no context, just numbers (numeric)

Minimum possible score was zero; maximum possible score was 16

The mathematical performance of public sector students is poor than all. It is almost half than the others, particularly in the test A, and B. All students show better performance in the numeric test as compared to others with language. Students of both exposures (using mathematics with foreign language and foreign context; using mathematics with foreign language and local context) have shown better performance/ ease in dealing with mathematics in their L1. It is very interesting to note 
that students with good background of English instruction (school 1) have shown ease in L1 version of test with a mean difference of 0.26 . The results project that public sector students feel comparatively more difficulty in mathematics in English. Mean difference of their performance in the English (test A) and Urdu (test B) is higher than that of others. Use of non-local context in mathematics is problem for all students. A point to be noted is that even students using/exposed to mathematics in foreign context are showing better performance in the local context.

\section{Students' Performance in Word Problems Presented in L1 (Urdu) and L2 (English)}

Table 6

Difference of Students' Performance in English (Test B) and Urdu (Test C)

\begin{tabular}{lllllll}
\hline Type of Test & $\mathrm{N}$ & $\mathrm{X}$ & $\mathrm{SD}$ & $\mathrm{df}$ & t-value & Sig. \\
\hline Test B (English) & 849 & 7.04 & 3.634 & 1676 & -5.380 & 0.000 \\
Test C (Urdu) & 829 & 7.95 & 3.305 & &
\end{tabular}

Test B- Foreign language (English as second language) and local context

Test C- Local language (Urdu) and local context

The analysis results showed Levene's F-Test for equality of variances is equal to $F=11.46$ and its probability value is equal to $\mathrm{p}=.001$ which indicates that both the populations have homogeneity of variance. An independent sample t-test (assuming equal variances) has been conducted to compare the students' performance in mathematical word problems presented in L1 (Urdu) and L2 (English) languages. There is a highly significant difference at 0.01 level of significance in scores for mathematical word problem in Urdu (Mean=7.95, SD=3.305) and English (Mean=7.04, SD=3.634) languages; $\mathrm{t}(1676)=-5.380$ and $\mathrm{p}=0.000$ (two tailed), the magnitude of difference in two means group ( Mean difference $=-0.913,95 \% \mathrm{CI}=-1.246$ to -0.580 ) is very small and Eta squared $=0.017$.

There occurs significant improvement in students' performance when we shift word problems from L2 to L1 (with a mean difference of-0.913).

Students' Performance in Word Problems Presented in L1 and Numeric

Table 7

Difference of Students' Performance in Urdu (Test C) and Numeric (Test D)

\begin{tabular}{lllllll}
\hline Type of Test & $\mathrm{N}$ & $\mathrm{X}$ & $\mathrm{SD}$ & $\mathrm{df}$ & t-value & Sig. \\
\hline Test C (Urdu) & 829 & 7.95 & 3.634 & \multirow{2}{*}{1672} & -10.339 & \multirow{2}{*}{0.000} \\
Test D (Numeric) & 845 & 9.65 & 3.305 & & & \\
\hline
\end{tabular}

Test C- Local language (Urdu) and local context

Test D- No language and no context, just numbers (numeric).

The results of analysis from table 7 Levene's F-Test for equality of variances is equal to $\mathrm{F}=4.310$ and its probability value is equal to $\mathrm{p}=.038$ which indicates that both the populations have homogeneity of variance at 5\% level of significance. An independent sample t-test (assuming equal variances) has been conducted to compare the students' performance in mathematical word problems presented in L1 (Urdu) and numeric (no language just numbers) format. There is a highly significant difference at 0.01 level of significance in scores of mathematical word problems for local language Urdu (Mean=7.95, $\mathrm{SD}=3.305$ ) and numeric (no language just numbers) format (Mean=9.65, $\mathrm{SD}=3.413) ; \mathrm{t}(1672)=-10.339$ and $\mathrm{p}=0.000$ ( close to zero for two tailed), the magnitude of difference in two means group ( Mean difference $=--1.698,95 \%$ CI -2.020 to -1.376 ) is moderate and Eta squared $=0.060$

The study explores that even if the word problems are offered in students' own language, the inclusion of language (foreign/local) in mathematics has significant effect on students' performance. Notable improvement in results has been observed when same word problems were offered in numeric.

Difference of Students' Performance in Foreign Language Foreign Context and Foreign Language Local Context

Table 8

Difference of Students' Performance in Test A (Foreign Language Foreign Context) and Test B (Foreign Language Local Context)

\begin{tabular}{lllllll}
\hline Type of Test & $\mathrm{N}$ & $\mathrm{X}$ & $\mathrm{SD}$ & $\mathrm{df}$ & t-value & Sig. \\
\hline Test A & 851 & 6.12 & 3.419 & \multirow{2}{*}{1698} & -5.357 & 0.000 \\
Test B & 849 & 7.04 & 3.634 & & \\
\hline
\end{tabular}

Test A- Foreign language (English as second language) and foreign context 
Test B- Foreign language (English as second language) and local context

The results indicate Levene's F-Test for equality of variances is equal to $\mathrm{F}=6.885$ and its probability value is equal to $\mathrm{p}=0.008$ which indicate that both the populations have homogeneity of variance at 5\% level of significance. An independent sample t-test (assuming equal variances) has been conducted to compare the students' performance in mathematical word problems presented in L1 (English) with foreign context (British) and in L2 (English) with students' own context (Pakistani). There is a highly significant difference at 0.01 level of significance in scores for foreign context (British) language (Mean=6.12, SD=3.419) and English) with students' own Pakistani (Mean=7.04, $\mathrm{SD}=3.634) ; \mathrm{t}(1698)=-5.357$ and $\mathrm{p}=0.000$ (two tailed), the magnitude of difference in two means group (Mean difference $=-0.917,95 \%$ CI -1.252 to -.581 ) is very small and Eta squared $=0.017$.

There occurs significant improvement in students' performance in the same word problems when offered in students' own context (though in L2) as compared to those in the foreign context.

Effect of Language and Context on Students' Performance in Word Problems of Addition, Subtraction, Multiplication, and Division

Table 9

Mathematical Skill \& Test Wise Scores

\begin{tabular}{lllllllllllll}
\hline & \multicolumn{3}{l}{ Addition } & \multicolumn{4}{l}{ Subtraction } & \multicolumn{4}{c}{ Multiplication } & \multicolumn{3}{l}{ Division } \\
\cline { 2 - 13 } Type of Test & $\mathrm{N}$ & $\mathrm{X}$ & $\mathrm{SD}$ & $\mathrm{N}$ & $\mathrm{X}$ & $\mathrm{SD}$ & $\mathrm{N}$ & $\mathrm{X}$ & $\mathrm{SD}$ & $\mathrm{N}$ & $\mathrm{X}$ & SD \\
\hline Test A & 851 & 1.63 & 1.089 & 851 & 1.57 & 1.103 & 851 & 1.53 & 1.202 & 851 & 1.40 & 1.171 \\
Test B & 849 & 1.80 & 1.147 & 849 & 1.76 & 1.143 & 849 & 1.78 & 1.237 & 849 & 1.70 & 1.212 \\
Test C & 829 & 2.02 & 1.132 & 829 & 1.98 & 1.090 & 829 & 2.06 & 1.164 & 829 & 1.88 & 1.175 \\
Test D & 845 & 2.36 & 1.135 & 845 & 2.52 & 1.008 & 845 & 2.45 & 1.206 & 845 & 2.32 & 1.235 \\
\hline
\end{tabular}

Test A- Foreign language (English as second language) and foreign context

Test B- Foreign language (English as second language) and local context

Test C- Local language (Urdu) and local context

Test D- No language and no context, just numbers (numeric)

Language affects students' performance in all the four basic skills of mathematical word problems. The result improves in all the skills as we eliminate the language element. Difference in mathematical word problems' context cause difference in students' performance in all the four basic skills. The performance improves in all the four skills as we localize the context of the word problems.

Discussion, Conclusions, and Recommendations

Findings of the study suggested the following considerations to be discussed:

Language proficiency \& mathematical performance. The most important finding of this study is that language holds a significant effect on students' performance in mathematics. Gradual elimination of language in the tests ensures improvement in students' performance. This proves that reduced language interference results in improvement of students' performance in mathematical skills. But this is also not deniable that language is an essential element of mathematics teaching and learning, particular to bi-multilingual situations.

At first step, the issue of language was reduced by introducing students' first language. There occurred significant improvement in the students' performance. Then, the language was eliminated, and students were offered with a numeric test in the same mathematical skills.

The score obtained almost double increase to the one occurred in the test in students' first language. The study suggests that students may face failure to solve mathematical word problems though they are able to attempt corresponding problems offered in purely numeric setting. This finding of the study offers support for those by Cummins, Kintsch, Reusser and Weimer (1988). Again, these findings reflect consistency with those of Hakuta, Santos and Fang (2013) that proficiency in language and that in mathematics seems shared, as lower proficiency in language inclines to translate into poorer performance in mathematics. It warrants that there is probability of confusing performance in mathematics with language skills.

It has usually been noticed in mathematics classes, particularly at lower levels, that to overcome the language barrier some students mainly depend on 'guessing' to adopt their solution strategy (for supportive view see Verschaffel \& De Corte, (1997) in chapter 3, p.34). They suppose 'altogether' stands for addition, 'left' or 'more' for subtraction and so on so forth. This is another approving point for relevance of language with mathematics. 
Mathematics and second language/ L1 advantage. Students' significantly better performance in their first language relates to our previous discussion on the relationship of language proficiency (in terms of reading skill) with mathematical performance. The supporters of the finding that L1 is the best language for utmost performance in mathematical word problems claim their view on account of students' proficiency in that language. In the present study we had some cases whose Urdu was their first language, but they had performed better in the word problems test offered in English. This provides evidence that L2 is not the issue, but language proficiency is the actual factor which works for enhanced performance in mathematical word problems. But this phenomenon is very rare where learners of English have been found performing better in mathematical word problems presented in English. It has already been reported that all the 867 participants of the study were Urdu natives. Only $44(5.1 \%)$ of them achieved better performance in the English test. But the rest 823(94.9\%) were found performing better in their first language i.e., Urdu. The former 44 students' better performance in English was actually due to the reason that they reported that though Urdu had been their first language, but then for the last 3-4 years they were most exposed to English at their school and outside school.

Students from all the three existing exposures in Pakistan performed significantly better in mathematical word problems offered in their first language (Urdu). This suggests that the use of students' first language facilitates solution to word problems, and they perform better in mathematics test given to them in their native language. This reinforces same findings from many as and Bernardo and Calleja (2005).

Low achievement in mathematics in English at the part of our ESL learners is consistent with interpretations of numberless studies conducted on bi/multilingual learners of English in different parts of the world (Barton, Chan, King, Neville-Barton \& Sneddon, 2005; Setati \& Barwell, 2006; Webb \& Webb, 2008).

The effect of language is not particular to a single mathematical skill. Almost equal effect of language on all the four basic skills of mathematics (addition, subtraction, multiplication, and division) suggests that mathematical complexity or simplicity of the skill is a separate issue; it has nothing to do with language. It demonstrates that language has independent effect on students' performance in solving mathematical word problems.

The issue of language is more acute at lower grades. The study observed that the lower is the grade, the wider is the gap between his mathematical performance in Urdu and English versions of tests. Other studies (Campbell, Nishio, Smith, Clark, Conant., Rust., ... \& Choi, 2014) have also pointed out that older students are less likely to face difficulty with regards to language and mathematics. Therefore, it is wise to suggest that at least at lower grades, students' own language should be the language of their mathematics. But this is still an open problem to decide where it is best to introduce foreign language in mathematics problems so that the abilities of students to solve mathematics may not be disturbed and hampered.

Better performance in L1 at the part of students even with good English background is another evidence in support of recommending the use of student's first language for mathematics education.

According to the findings of this study our school students are already weak in mathematics. This issue of language not only hampers their performance but most probably it must be demotivating them towards mathematics learning.

Our public sector students and the issue of language in mathematics. At the part of public sector students' high ratio of difference in their performance in the English and Urdu versions of mathematics tests is alarming with regards to present movement of Pakistani government from Urdu to English as medium of instruction. The study found that our public sector students are suffering nearly $20 \%$ disadvantage of second language interference in mathematical word problems.

On the other side of the picture, we are aware of the condition of our students in English as a second language. Despite heavy efforts to improve English of our students, getting pass marks in English is still a dream even at graduate levels. We are still in dearth of proficient teachers of English as a second language. However, discussion on the condition of English in our situation is not a basic concern of this study. But keeping this picture in mind, do we still think it wise to adopt English as language for major content subjects like mathematics and science. Among the favourers of English as medium of instruction, along with other benefits, there is a common belief that using English in the 
content subjects can be a good hand for improvement of students' proficiency in this language. Let us suppose for a moment, they are correct in their belief that this can accelerate our students' proficiency in English. If we are not considering the reality which this study supports that use of English (as second language) snubs our students' performance in mathematical skills, then we must accept that in this case the basic aim of teaching mathematics is not mathematics skills but second language. If we want to teach mathematics for mathematics, we must acknowledge that second language is a barrier for our students in performing their utmost in mathematics. Aligned with this research, a large number of studies on this problem conducted in bilingual situations in different parts of the world (such as Bernardo \& Calleja, 2005; Neville-Barton \& Sneddon, 2005; Setati \& Barwell, 2006; Webb \& Webb, 2008) have recognized that language is a strong factor affecting students' performance in mathematics. It implies immediate revision of the policy with regards to the use of language in mathematics at lower grades.

This demonstration of the study finds support from empirical works of, Pungut and Shahrill, (2014) who see high achievement in learner's native language at school.

Language and mathematics assessment. Difference in students' results with change or elimination of language raises a question whether assessments taken with no consideration of the element of language offer exact measurements of mathematical abilities of our students (see Abedi, 2002).

Larsson, (2015) report that using an un-acquainted language in a test is the most recurrent cause for its in-appropriateness. In this context, while taking measurement of mathematics achievement, it becomes imperative that all aspects of language interference in mathematical performance be considered.

Situation context and mathematical performance. Improvement in performance with localization of the situation context in the word problems proposes that the element of context in the word problems also attains an important factor. The importance of the element of context of word problems is more strengthened when the study finds that even students taught mathematics with foreign context in their school are giving more performance in the localized version of the test. It exhibits that the students using mathematics books in English with foreign context are suffering more as along with the issues of language they are faced with the issue of context as well.

On the other hand, the claim of teaching application of mathematics to real life situations can only be justified when students learn mathematics connected with their own context.

The students' improvement in performance with localization of word problems' context avails reinforcement from Saxe (2015). Same findings have been confirmed from Davis-Dorsey, Ross, and Morrison (1991). Socio-culturally focused studies expose that some sort of context can provide some help for students in reaching correct solutions (Blum, 2015).

Some studies have taken context as culture. Their findings also confirm that mathematics is not culture free and introducing culturally relevant word problems to students was beneficial (Singer, Ellerton \& Cai, 2015; Tanujaya, Prahmana \& Mumu, 2017).

The study proposes that word problems modeled in students' known context can increase their achievement in solving word problems by developing their motivation and including their knowhow from other than school. Moschkovich (2002), and National Council of Teachers of Mathematics $(1989,2000)$ have already pointed out consistent findings.

Setati et al. (2009) and Leonard (2017) support that poor performance in mathematical word problems cannot only be linked to students' poor language proficiency as well as the factor of students' context where he is living in and familiar with.

Further, the study suggests that attainment of accurate assessments seek for full fledge consideration of the element of context while assessing the students who are facing mathematics in the foreign context in their learning and assessments. Otherwise, it is not justified to claim that the assessments offer correct results of students' mathematical abilities.

\section{Limitations of the Study}

The findings of this study should be considered in the light of the following limitations:

Providing all grade 1, 2 and 3 students for four comprehensive tests at different intervals was really a big interference in the school routines. Therefore, availing at least one school from each stratum itself was very hard for the researcher who was not the part of their system. Further, conducting four tests for each group and then analyzing them also was not an easy task. So, the study could not include representative sample of the total population. In this way, this factor of the sample 
limits generalizability of the results of this study. In such cases 'proximal similarity' is suggested. Or the findings of the study may be applicable to situations on grounds of similar sample and context. The nature of sample has been well explained in the study to help others for determining the level of comparability of the findings of the study to their context.

\section{Recommendations}

The study suggests that the use of language in mathematics should be minimized, particularly at lower grades. If some degree of language is essential, most preferably, it should be students' first language. For accurate performance in mathematical problem solving, the reading ability of the students in the language of word problems needs to be improved. If the usage of second language as medium of instruction in mathematics is inescapable, maximum exposure to that language should be made possible. In this case in our situation, the study recommends notional-functional syllabus. The language teaching in the notional-functional approach sees language as skills required to accomplish content objectives. The focus, here, is, not on teaching communication skills for general purposes, but the aim of this approach is to teach the use of language for specific academic purposes. Here, in the notional-functional approach, language is taken to be specific language functions to be learned. In regard of mathematics, notions stand for specific aspects of the content of the discipline. Functions refer to:

i. General language activities, such as giving and receiving information, expressing, and discovering opinions.

ii. Mathematics-specific language functions such as representation, discussion, translation, verbalization etc.

Blum (2015) has offered some general guidelines to develop a notional functional second language curriculum for a content subject.

Further, the study recommends teaching mathematical word problems in students' most familiar context.

\section{References}

Blum, W. (2015). Quality Teaching of Mathematical Modelling: What Do We Know, What Can We Do? In The proceedings of the 12th international congress on mathematical education (pp. 73-96). Springer, Cham.

Barton, B., Chan, R., King, C., Neville-Barton, P., \& Sneddon, J. (2005). EAL undergraduates learning mathematics. International Journal of Mathematics in Science and Technology, 36(7), 721-729. doil:0.1080/00207390500270950.

Bernardo, A. B. I. (2002). Language and mathematical problem solving among bilinguals. The Journal of Psychology, 136, 283-297.

Bernardo, A. B. I., \& Calleja, M. O. (2005). The effects of stating problems in bilingual students' first and second languages on solving mathematical word problems. The Journal of Genetic Psychology, 116, 117-128.

Brahier, D. (2016). Teaching secondary and middle school mathematics. Routledge.

Campbell, P. F., Nishio, M., Smith, T. M., Clark, L. M., Conant, D. L., Rust, A. H., ...\& Choi, Y. (2014). The relationship between teachers' mathematical content and pedagogical knowledge, teachers' perceptions, and student achievement. Journal for Research in Mathematics Education, 45(4), 419-459.

Cummins, D. D., Kintsch, W., Reusser, K., \& Weimer, R. (1988). The role of understanding in solving word problem. Cognitive Psychology, 20, 405-438.

Gurganus, S. P. (2017). Math instruction for students with learning problems. Taylor \& Francis.

Hakuta, K., Santos, M., \& Fang, Z. (2013). Challenges and opportunities for language learning in the context of the CCSS and the NGSS. Journal of Adolescent \& Adult Literacy, 56(6), 451-454.

Hoth, J., Döhrmann, M., Kaiser, G., Busse, A., König, J., \& Blömeke, S. (2016). Diagnostic competence of primary school mathematics teachers during classroom situations. ZDM, 48(12), 41-53.

Howie, S. J. (2003). Language and other background factors affecting secondary pupils' performance in Mathematics in South Africa. African Journal of Research in Science, Mathematics and Technology Education, 7, 1-20.

Howie, S. J. (2004). A national assessment in mathematics within international comparative assessment. Perspectives in Education, 22, 149-162. 
Kempert, S., Saalbach, H., \& Hardy, I. (2011). Cognitive benefits and costs of bilingualism in elementary school students: The case of mathematical word problems. Journal of educational psychology, 103(3), 547.

Larsson, M. (2015). Orchestrating mathematical whole-class discussions in the problem-solving classroom: Theorizing challenges and support for teachers (Doctoral dissertation, Mälardalen University).

Leonard, J. (2017). Culturally specific pedagogy in the mathematics classroom: Strategies for teachers and students. Routledge.

Mizala, A., Martínez, F., \&Martínez, S. (2015). Pre-service elementary school teachers'

expectations about student performance: How their beliefs are affected by their mathematics anxiety and student's gender. Teaching and Teacher Education, 50, 70-78.

National Council of Teachers of Mathematics (2000). Principles and standards of school mathematics. Reston, VA: author.

Oviedo, G. C. B. (2005). Comprehending algebra word problems in the first and second languages. In J. Cohen, K.T. McAlister, K. Rolstad \& J. MacSwan (Eds.), Proceedings of the $4^{\text {th }}$ International Symposium on Bilingualism (pp. 267-295). Somerville, MA: Cascadilla Press.

Pungut, M. H. A., \&Shahrill, M. (2014). Students' English language abilities in solving mathematics word problems. Mathematics Education Trends and Research, 2014(unknown), 1-11.

Ri'orda', M. N., \& Donoghue, J. O. (2007). Language, mathematics learning and gaeilgeoiri': A study of educational transitions in Irish education. In S. Close, D. Corcoran \& T. Dooley (Ed.), Proceedings of Second National Conference on Research in Mathematics Education (pp. 170-183). Dublin: St. Patrick's College.

Roberts, G., \& Bryant, D. (2011). Early mathematics achievement trajectories: English-language learner and native English-speaker estimates, using the Early Childhood Longitudinal Survey. Developmental Psychology, 47(4), 916.

Saxe, G. B. (2015). Culture and cognitive development: Studies in mathematical understanding. Psychology Press.

Setati, M., \& Barwell, R. (2006). Discursive practices in two multilingual mathematics classrooms: An international comparison. African Journal for Research in Mathematics, Science and Technology Education, 10(2), 27-38.

Setati, M., Chitera, N., \& Essien, A. (2009). Research on Multilingualism in mathematics education in South Africa: 2000-2007. African Journal of Research in MST Education, Special Issue, 6580.

Singer, F. M., Ellerton, N. F., \&Cai, J. (2015). Mathematical problem posing. New York: Springer. http://doi. org/10.1007/978-1-4614-6258-3.

Takeuchi, M. A. (2016). Friendships and group work in linguistically diverse mathematics classrooms: Opportunities to learn for English language learners. Journal of the Learning Sciences, 25(3), 411-437.

Tanujaya, B., Prahmana, R. C., \& Mumu, J. (2017). Mathematics instruction, problems, challenges, and opportunities: A case study in Manokwari regency, Indonesia. World Transactions on Engineering and Technology Education, 15(3), 287-291.

Verschaffel, L., \& De Corte, E. (1997). Teaching realistic mathematical modeling and problem solving in the elementary school. A teaching experiment with fifth graders. Journal for Research in Mathematics Education, 28, 577-601.

Webb, L., \& Webb, P. (2008). Introducing Discussion into Multilingual Mathematics Classrooms: An Issue of Code Switching. Pythagoras: Journal of the Association for Mathematics Education of South Africa, 67, 26-32. 